\title{
Anatomic Structure, System, or Substance
}

National Cancer Institute

\section{Source}

National Cancer Institute. Anatomic Structure, System, or Substance. NCI Thesaurus.

Code C12219.

A human biological structure, fluid or other substance; excludes single molecular entities. 